\title{
Flexibility in Personal Management by Global Budgets: The Case of Lower Saxony, Germany Michael Daxner
}

\section{INTRODUCTION}

The German system of budgeting and accounting higher education expenditures has been very inflexible and, unlike in other European states, has never been turned into an effective financial administration. This comes from a perception that has never recognized universities as sometimes very large enterprises or corporations. The academic corporation, with all its freedom and liberties, has never really been accepted as a business as well, albeit having public responsibility, and acting as an important player in the economic system.

The present system is called 'cameralistic'. According to a very detailed budget in the legislation, the university is entitled to spend money in accordance with even more detailed financial regulations. This has nothing to do with the estimates, which are prepared two years in advance and submitted to the administration which prepares the draft legislation. The parliamentary budget describes very meticulously for each university every staffing position and all heads of expenses. Thus, this system does not require accounting, neither is it balance- or cost-oriented, and it does not imply strict control. Only the appropriateness of expenditure is supervised by the chancellor (German terminology) of the university and the Auditor-General of the state.

\section{DEFICIENCIES}

The deficiencies of this system are evident. The major disadvantages are:

- There is no relation between the estimates and the annual endowment. The estimates reflect the needs of the academic institution: the budget given is a fiscal compromise by the state, which sustains the institution.

- There is no mechanism for control. Almost all parts of the budgets are either inflexible (staffing structure and wages) or extrapolated from the status quo.

- There is no accounting according to the effective rules of costorientation and balance-transparency.

Universities do not, therefore, receive enough autonomy in the allocation of their resources. There is no motivation for their members to commit themselves to reasonable economic procedures, because everything important is regulated by the state's administration. The administration of the university cannot act, as appropriate, as an independent enterprise that tries to obtain what it requires at lowest costs, and to sell what is available to a university for selling.

\section{REFORM}

The reform model of the 'Global Budget' (Globalhaushalt) is part of a wide provision that the government of Lower Saxony has adopted in order to strengthen the autonomy of the universities, to raise the level of accountability and responsibility to the public and their immediate clients (students, employers, social and economical systems), and to restore the relationship between the academic mission and the competent administration of knowledge in a period of a cataclysmic shake up of the welfare state.

Three universities in Lower Saxony will be partners in this experiment which is designed for a period of ten years (!), during which a prototype for a new budgeting system will be developed. The idea is that each university draws up its own budget that contains expected costs, distribution and the rules of intrainstitutional transferability of resources. This budget is checked against the mission and the development plan of the university, and must be negotiated with the state, ie with the legislature via the administration. The main difference will be that from the moment it receives the global sum of the annual budget to the university, it will be fully responsible for allocating and controlling its resources like a state-owned business. It is very important to note that this will be the legal construction. Even when the universities attain full managerial power over their budget, they will not be free enterprises, but state businesses. This creates many new problems for the legal and administrative hierarchy.

Inside the university, this model will change considerably. There are some very important questions to be answered:

- Who is responsible for the spending of money?

- How are costs and expected results being calculated?

- How can we introduce transparent procedures?

- How can the new distribution of liability become internalized?

\section{ANSWERS}

The answers are somewhat complex as they affect many different aspects of a university. The pragmatic level is easiest to approach: the introduction of effective accounting requires training, computer-equipment and just a few procedures of changing responsibilities. It is more complex to shift the decision-making process and its procedures. First of all, all future budget decisions will imply a decision concerning the allocation of resources. Any change in a budget which is agreed will require a balancing proposal as to from where the new expenses are to be covered. The relationship between administrators and decision-making bodies must be reshaped as well as the collusive interdependence between 'science' and 'administration'. The transfer from academic decisions into economic practice meets many reservations, eg the anxiety that minorities might become discriminated against, and that power will be shifted towards the president and the deans, and away from the self-governing bodies of the university. There is also the danger that the state wants to rid itself of the conflicts of distribution of resources, when budget cuts reduce the overall contribution to the annual budget.

One of the main advantages of the new system will be that the staffing structure will become more flexible and adequate for the needs of a modern university. Of course, the university will be bound by all regulations that come from the German Civil Service and contracts between the academic staff unions. But within these schemes there is a broad range of possibilities for staff development. It is this part of the model that will most likely change the attitudes of the members of the university in a remarkable way. They will be able to construct their working environment themselves and they will also be responsible for it. This, in combination with internal overhead-regulations, crediting, building up of funds and reserves, will not interfere with the university in carrying out its academic duties, but will strengthen it to achieve better what it cannot achieve at present because of fiscal restraints.

\section{ENVOI}

Altogether, this model will be a contribution to restoring public trust in universities and thus become part of the reforms the German system of higher learning will have to undergo in the near future. 